\title{
Demystification of Vedic Multiplication Algorithm
}

\author{
Manohar Mathur1, Aarnav² \\ ${ }^{1}$ Metro Railway Electrical Engineering Expert, Lucknow, India \\ ${ }^{2}$ DPS, Lucknow, India \\ Email: manoharmathur2302@gmail.com
}

How to cite this paper: Mathur, M. and Aarnav (2017) Demystification of Vedic Multiplication Algorithm. American Journal of Computational Mathematics, 7, 94-101.

https://doi.org/10.4236/ajcm.2017.71008

Received: December 15, 2017

Accepted: March 28, 2017

Published: March 31, 2017

Copyright ( $\odot 2017$ by authors and Scientific Research Publishing Inc. This work is licensed under the Creative Commons Attribution International License (CC BY 4.0).

http://creativecommons.org/licenses/by/4.0/

Open Access

\begin{abstract}
The Vedic multiplication algorithm is a very fast way of oral calculation. However, the basis of the algorithm is not available so far. The present paper demystifies the general Vedic algorithm for multiplication by establishment of foundation of the Vedic algorithm of product finding through end results of conventional multiplication. This novel approach, i.e., finding algorithm from the end results of conventional calculations may be useful in devising algorithms similar to Vedic in cases of other calculations. Though the availability of cheap calculators made the Vedic Method obsolete, the present trend resurrected Vedic algorithms by their use in the design of computer processors for enhancing speed and performance.
\end{abstract}

\section{Keywords}

Vedic, Demystification, Multiplication, Vertically, Crosswise, Urdhvak, Tiryak, Computer, Processor

\section{Introduction}

Vedic mathematics [1]-[6] is undeniably a faster way of doing oral calculations. It deserves all applause. However, due to provision of cheap calculators for common people and students today, Vedic Mathematics started losing its sheen and it appeared that it would be finally rejected. Nonetheless, the speciality of Vedic Mathematical algorithms is now well recognized as per survey [7] and nowadays it is extensively used in computer processor designs [8] [9] [10] for speeding up performance. It has also been recommended for use in High-Per-formance FIR filter implementation [11], image compression [12], area and speed of wisely superior multiplier and unit multiplier [13], reduced-bit multiplication algorithm [14], multipliers as the integral components in the design of many high performance 
FIR filters, image and digital signal processors [15] [16]. In spite of its so many alluring benefits and awesome speed, the Vedic Multiplication Algorithm remains mystical as the basics of these are still unknown. The natural curiosity to get the basis of Vedic algorithm has given birth to the objective of this research to remove the veil of mysticism from Vedic Multiplication Algorithm. This research institutes the very foundation and logic of Vedic Multiplication Procedure for general multiplication.

There are several Vedic algorithms for multiplication including a general one, which is universal, whereas each of other Vedic algorithms for multiplication suits a special situation.

Scope of this research is confined to finding the logic of Vedic Multiplication Algorithm for multiplication of general type as it has universal application and this finds product of a several-digit multiplicand and several-digit multiplier.

Interestingly, this research is purely based on end results of conventional multiplication procedure and this approach may be used in cases of other complicated mathematical procedures for finding shortcut-algorithms like the Vedic approach.

Results of this avant-garde research are very encouraging and verifiable. Besides, it may be path finder.

\section{Basis of Vedic Multiplication Algorithm}

It may be interesting to note that the Vedic algorithm is based on the reorganization of conventional multiplication method only. In Vedic jargon, the algorithmic procedure is described in terms of urdhvak (vertical multiplication) and tiryak (crosswise multiplication) operations. The purpose of this work is to handover the very basis of the Vedic formulae to the users which can be a very valuable asset to them for clear understanding.

The ordinary multiplication method is used here as a vehicle in evolving the Vedic Sutra (Algorithm) starting with multiplication of 2-digit multiplicand and 2-digit multiplier. Also, alphabetical symbols shall be used to represent digits in doing so. This will be extended later for finding products of a several-digit multiplicand by another several-digit multiplier.

\section{Evolution of Vedic Algorithm}

\subsection{Evolution of Vedic Algorithm of Multiplication of a 2-Digit Multiplicand and 2-Digit Multiplier}

Let $\boldsymbol{a}_{1}$ and $\boldsymbol{a}_{2}$ be digits at units and tens of multiplicand. Similarly, let $\boldsymbol{b}_{1}$ and $\boldsymbol{b}_{2}$ represent the digits at units and tens of multiplier. With these assumptions, the conventional multiplication is performed to evolve the algorithm for such product finding tasks. A conventional multiplication table is given below in Table 1.

Critical observation of the result row of Table 1 is the basis of evolution of Vedic Sutras or Vedic Formulae for multiplication shortcut. For this reason, Table 2 is made without showing the operations of multiplication.

Result at units $b_{1} a_{1}$ prompts that this is the result of vertical multiplying the digits positioned at units for both multiplier and multiplicand $\left(b_{1}\right.$ and $\left.a_{1}\right)$. In Vedic jargon, this is known as urdhvak. It is a Sanskrit word and when it is translated, it 
means upward or rising up or vertically up. Here $a_{1}$ is vertically up or urdhvak to $b_{1}$. This is the Vedic formula to get quickly the digit of product at units. This is marked by arrows here for better understanding.

Observation of result at Tens $\boldsymbol{b}_{2} \boldsymbol{a}_{1}+\boldsymbol{b}_{1} \boldsymbol{a}_{2}$ points out that the sum of crosswise multiplication 1) of digit at Units of multiplier with digit at Tens of multiplicand and crosswise multiplication 2) of digit at Tens of multiplier with digit at Units of multiplicand. The result at Hundreds, i.e., $\boldsymbol{b}_{2} \boldsymbol{a}_{2}$ indicates that this is vertical or urdhvak multiplication of digits at the tens for both multiplier and multiplicand. This is similar to getting result at units.

Lemma: In all product finding cases, the result of first place, i.e., units and last place (depending on number of digits) are vertical (urdhvak) products.

It may be noted that like conventional multiplication, carry, if any, is to be carried forward for addition to next higher place value.

Example 1: find product 34 and 67.

The above problem is tabulated in Table 3.

Table 1. Table of conventional multiplication of a 2-digit variable number with another 2-digit variable number.

\begin{tabular}{llll}
\hline $\begin{array}{l}\text { Tags for position of digits for place values } \\
\text { Description, operations and result }\end{array}$ & Hundreds & Tens & Units \\
\hline Multiplicand & & $a_{2}$ & $a_{1}$ \\
Multiplier & & $b_{2}$ & $b_{1}$ \\
First operation & $b_{1} a_{2}$ & $b_{1} a_{1}$ \\
Second operation & $b_{2} a_{2}$ & $b_{2} a_{1}$ & $X$ \\
Result of product & $b_{2} a_{2}$ & $b_{1} a_{2}+b_{2} a_{1}$ & $b_{1} a_{1}$ \\
\hline
\end{tabular}

Table 2. Table 1 after deletion of operations.

Tags for position of digits for place values $\longrightarrow$ Hundreds
Description, operations and result
Multiplicand
Result of product

Table 3. Tabular form of the above multiplication problem.

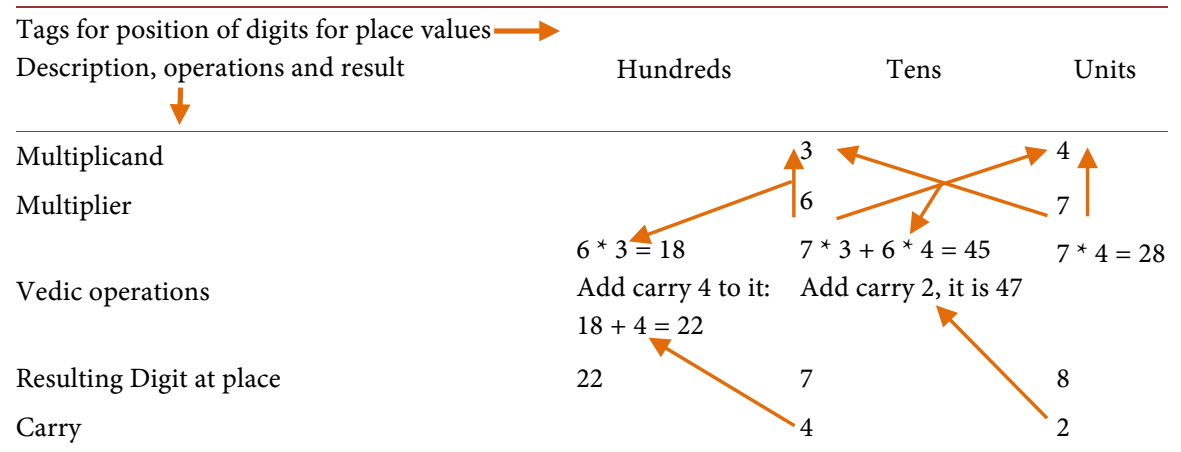


So, $34 * 67=2.278$.

Example 2: Find $78 * 59$.

Orally $9 * 8=72.2$ is kept as result at units whereas 7 is carry. $9 * 7+5 * 8=$ $63+40=103$. Adding carry 7 to it, it is 110 . So, 0 is retained as answer digit at tens and 11 is carry. Lastly $7 * 5=35$. Adding carry 11 to it, it is now 46 . This goes to hundreds. Therefore the final answer is 4602 .

\subsection{Evolution of Vedic Algorithm of Multiplication of a 3-Digit Multiplicand with Another 3-Digit Multiplier}

Let $\boldsymbol{a}_{1}, \boldsymbol{a}_{2}$ and $\boldsymbol{a}_{3}$ be digits at units, tens and hundreds respectively of multiplicand. Similarly, let $b_{1}, b_{2}$ and $b_{3}$ be digits at units, tens and hundreds respectively of multiplier. With these assumptions, the conventional multiplication is performed to evolve the Vedic algorithm for product finding tasks. Conventional multiplication table is given in Table 4.

From the result row in Table 4, it can be visualized that the Vedic formulae for finding product's digits at units and ten-thousands would be same as in case of multiplication of 2-digit variable number by another 2-digit variable number. Here ten-thousandth place is the last position and hence the last digits of multiplicand and multiplier will be multiplied vertically (urdhvak). As in previous case, Table 5 is made after deleting the rows for operations and keeping result at only hundreds.

Observations of results at hundreds:

1) $b_{1} a_{3}$ is found after multiplying multiplier's digit at tens with multiplicand's digit at hundred. This is shown by slant arrow i.e. crosswise or tiryak of Vedic

Table 4. Table of conventional multiplication of a 3-digit variable number with another 3-digit variable number.

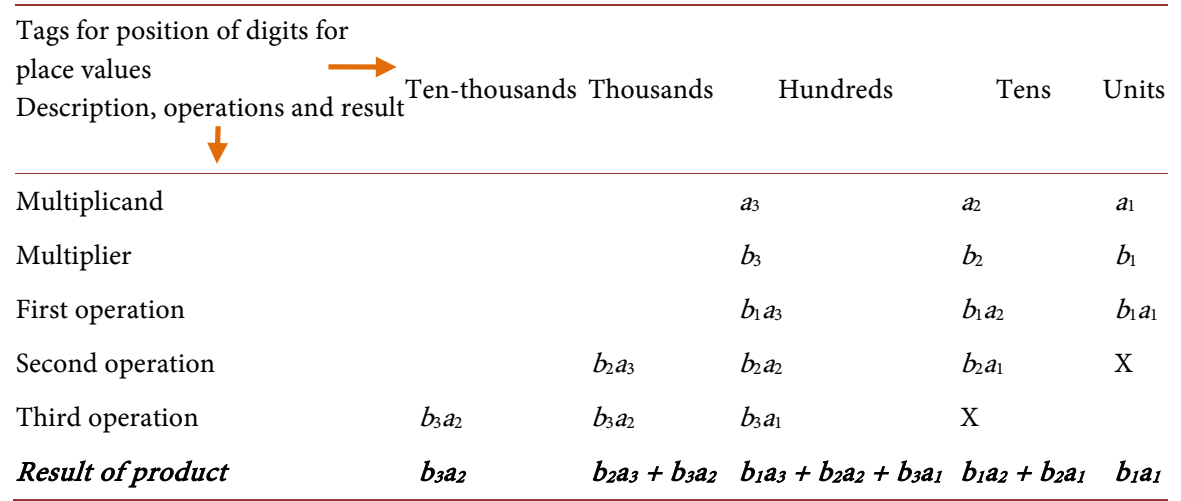

Table 5. Table 4 after deletion of operations.

Tags for position of digits for place values $\longrightarrow$ Ten-thousands
Description, operations and result


multiplication.

2) $\boldsymbol{b}_{3} \boldsymbol{a}_{1}$ is also obtained by multiplying multiplier's digit at hundreds by multiplicand's digit at units crosswise or tiryak way.

3) $\boldsymbol{b}_{2} \boldsymbol{a}_{2}$ is the result of finding product of digits at tens for both multiplicand and multiplier vertically or in urdhvak way.

Table 5 is now made after deleting all results save result at thousands to find Vedic algorithm to get product's digit at this place. Also, forget the digits at units now and onwards for the sake of calculations. Therefore, the column for units has been deleted.

Observations of result at thousands are in Table 4.

1) $b_{2} a_{3}$ is crosswise or tiryak product of multiplier's digit at tens and multiplicand's digit at hundred. This is shown by arrow in Table 6.

2) Similarly, $b_{3} a_{2}$ is also crosswise or tiryak product of multiplier's digit at hundreds and multiplicand's digit at tens. This is shown by arrow in Table 6.

Table 3 is reproduced below as Table 7 to observe result at ten-thousands. Digit at ten-thousands is $\boldsymbol{b}_{3} \boldsymbol{a}_{2}$, which is nothing but vertical multiplication of digits at hundreds for both multiplier and multiplicand. It is noteworthy to keep in mind that results at extreme places (here units and ten-thousands) are always vertical multiplications. This rule is universally applicable to multiplication of any-digit number by other any-digit number.

Example 1: Find product of 467 and 235.

The above problem is tabulated below in Table 8 .

Therefore, $467 * 235=109,745$.

Proceeding this way, one can find formulae for getting the result of multiplication of an n-digit multiplicand by n-digit multiplier. As an example, an 8-digit

Table 6. Table showing crosswise or Tiryak multiplications to get result at the thousands position.

Tags for position of digits for place values $\longrightarrow$ Ten-thousands
Description, operations and result
Multiplicand
Multiplier
Result of product

Table 7. Reproduced Table 3 for result at ten-thousand.

\begin{tabular}{|c|c|c|c|c|c|}
\hline $\begin{array}{l}\text { Tags for position of digits for place } \\
\text { Description, operations and result } \\
\downarrow\end{array}$ & Ten-thousands & Thousands & Hundreds & Tens & Units \\
\hline Multiplicand & & & $4^{a_{3}}$ & $a_{2}$ & $a_{1}$ \\
\hline Multiplier & & & $b_{3}$ & $b_{2}$ & $b_{1}$ \\
\hline First operation & & & $b_{1} a_{3}$ & $b_{1} a_{2}$ & $b_{1} a_{1}$ \\
\hline Second operation & & $b_{2} a_{3}$ & $b_{2} a_{2}$ & $b_{2} a_{1}$ & $\mathrm{X}$ \\
\hline Third operation & $b_{3} a_{2}$ & $b_{3} a_{2}$ & $b_{3} a_{1}$ & $\mathrm{X}$ & \\
\hline Result of product & $b_{3} a_{2}$ & $b_{2} a_{3}+b_{3} a_{2}$ & $b_{1} a_{3}+b_{2} a_{2}+b_{3} a_{1}$ & $b_{1} a_{2}+b_{2} a_{1}$ & $b_{1} a_{1}$ \\
\hline
\end{tabular}


multiplicand is multiplied by 8-digit multiplier in order to show the efficacy of the findings of this research. The Vedic formulae are worked out on the basis of conventional multiplication output. Table 9 shows the conventional multiplication of an 8-digit multiplicand by 8 -digit multiplier. From this conventional multiplication result, the product of any two 8-digit numbers can be orally found. The end results of conventional product finding in Table 9 is used to get the Vedic formulae for such product finding. The next table, Table 10, uses this algorithm to find the product of 8-digit multiplicand and 8-digit multiplier orally.

Example: Find the product of 10,231,021 and 21,021,103.

Table 8. Table for Vedic multiplication of above problem.

\begin{tabular}{|c|c|c|c|c|c|}
\hline $\begin{array}{l}\text { Tags for position of digits for } \\
\text { place values } \\
\text { Description, operations and result }\end{array}$ & Ten-thousands & Thousands & Hundreds & Tens & Units \\
\hline Multiplicand & & & 4 & 6 & 7 \\
\hline Multiplier & & & 2 & 3 & 5 \\
\hline Operations & $\begin{array}{l}\qquad 4^{*} 2=8 \\
\text { Adding } 2 \text { carry it is } 10\end{array}$ & $\begin{array}{c}4 * 3+2 * 6=24 \\
\text { Adding } 5 \text { carry it is } 29\end{array}$ & $\begin{array}{c}5 * 4+2 * 7+6 * 3=52 \\
\text { Adding } 5 \text { carry it is } 57\end{array}$ & $\begin{array}{c}5^{*} 6+3 * 7=51 \\
\text { Adding } 3 \text { carry it is } 54\end{array}$ & $7 * 5=35$ \\
\hline Resulting Digit & 10 & 9 & 7 & 4 & 5 \\
\hline Carry & & 2 & 5 & 5 & 3 \\
\hline
\end{tabular}

Table 9. Table of conventional multiplication of an 8-digit number by another 8-digit number.

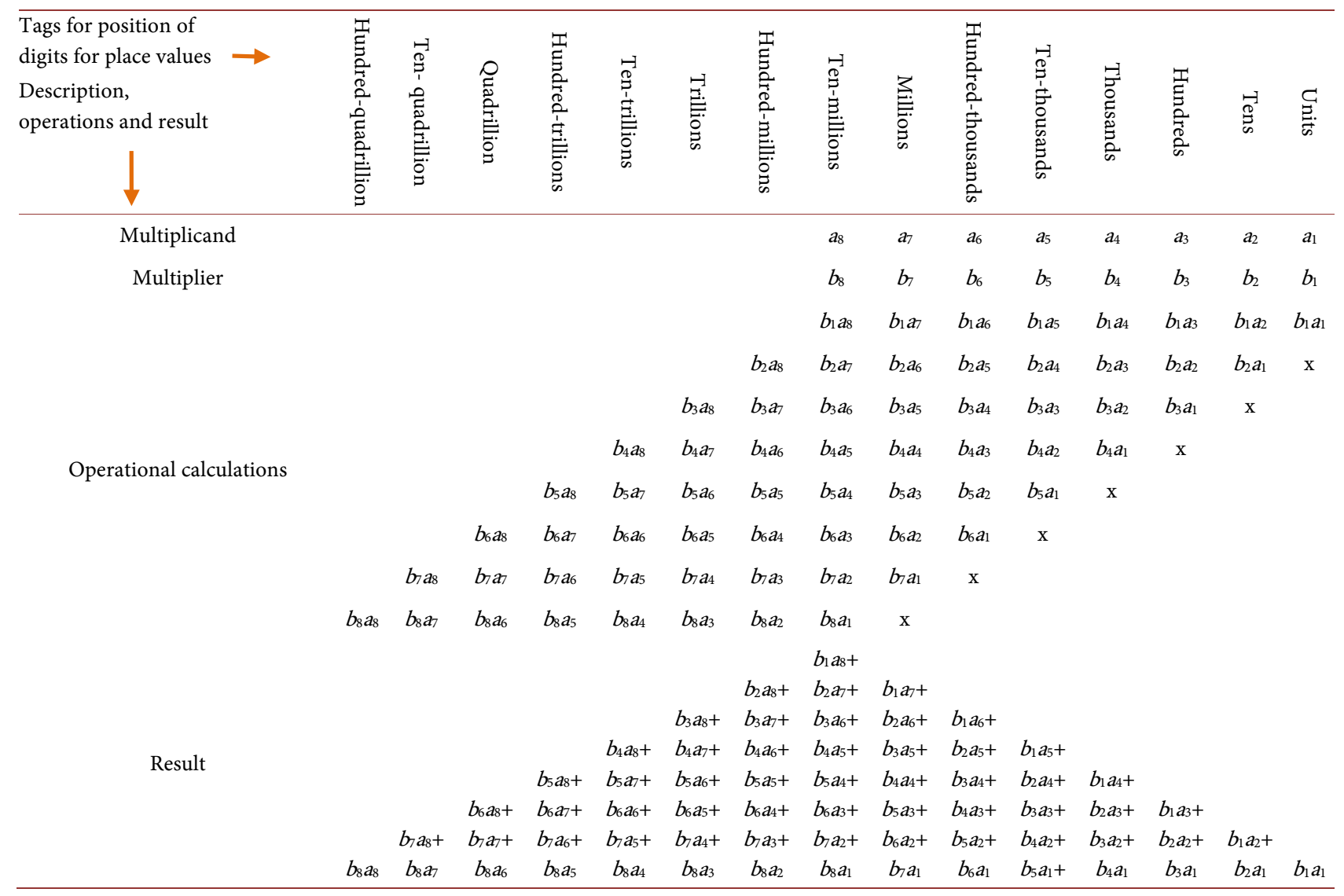


Table 10. Table of Vedic multiplication for above problem.

\begin{tabular}{|c|c|c|c|c|c|c|c|c|c|c|c|c|c|c|c|}
\hline Tags for position of digits for place values $\longrightarrow$ & 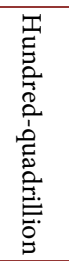 & 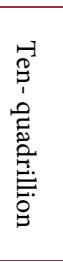 & 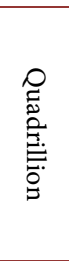 & 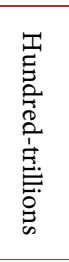 & 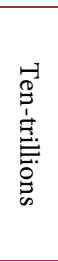 & 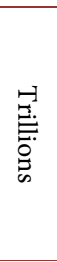 & 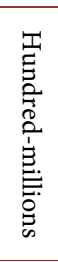 & 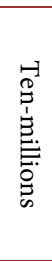 & 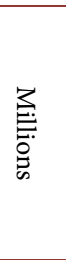 & 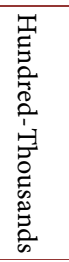 & 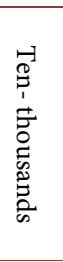 & 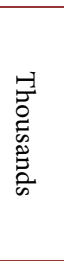 & 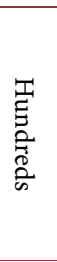 & $\overrightarrow{9}$ & 实. \\
\hline Multiplicand & & & & & & & & 1 & 0 & 2 & 3 & 1 & 0 & 2 & 1 \\
\hline Multiplier & & & & & & & & 2 & 1 & 0 & 2 & 1 & 1 & 0 & 3 \\
\hline Operations & $2 * 1$ & $\begin{array}{l}* 1+ \\
2 * 0\end{array}$ & $\begin{array}{c}0 * 1 \\
2 * 2+ \\
0 * 1\end{array}$ & $\begin{array}{l}2 * 1+ \\
2 * 3+ \\
0 * 0+ \\
2 * 1\end{array}$ & $\begin{array}{l}1 * 1+ \\
2 * 1+ \\
0 * 2+ \\
1 * 3+ \\
2 * 0+\end{array}$ & $\begin{array}{l}* 1+ \\
2 * 0+ \\
* 1+ \\
* 1+ \\
2^{*} 1+ \\
0 * 3\end{array}$ & $\begin{array}{l}0 * 1+ \\
2 * 2+ \\
0 * 1+ \\
1 * 0+ \\
1 * 2+ \\
0 * 1+ \\
3 * 2\end{array}$ & $\begin{array}{l}3 * 1 \\
2 * 1 \\
0 * 0 \\
1 * 2 \\
2 * 1 \\
0 * 0 \\
3 * 1 \\
2 * 1\end{array}$ & $\begin{array}{l}3 * 0+ \\
1 * 1+ \\
2^{*} 0+ \\
0 * 2+ \\
3{ }^{*} 1+ \\
2 * 0+ \\
1 * 1\end{array}$ & $\begin{array}{l}3 * 2+ \\
0 * 1+ \\
03+ \\
2 * 2+ \\
* 1+ \\
1 * 0\end{array}$ & $\begin{array}{l}3 \\
* 3+ \\
2 \\
* 1+ \\
* 0+ \\
* 0+ \\
1 * 0\end{array}$ & $\begin{array}{l}3 * 1+ \\
* 1+ \\
* 1+ \\
{ }^{*} 0+ \\
1 * 2\end{array}$ & $\begin{array}{l}* 0+ \\
* 1+ \\
2 * 0\end{array}$ & $\begin{array}{l}* 2+ \\
0 * 1\end{array}$ & $3 * 1$ \\
\hline Result & 2 & 1 & 5 & 0 & 6 & 7 & 3 & 4 & 6 & 2 & 3 & 6 & 1 & 6 & 3 \\
\hline Carry & & & & 1 & & & 1 & 1 & & 1 & 1 & & & & \\
\hline
\end{tabular}

This example problem is tabulated in Table 10 .

Therefore, $10,231,021 * 21,021,103=21,506,734,623$.

\section{Conclusions}

1) The basis of the Vedic general multiplication algorithm can be found from the end results of ordinary multiplication. This demystifies the Vedic algorithm for general multiplication.

2) The approach of this paper may be used to find algorithm shortcuts for other types of arithmetical calculations.

3) A Vedic algorithm for the multiplication of a n-digit multiplicand by $\mathrm{n}$-digit multiplier can be easily obtained by using alphabetic variables in lieu of numerals in the general conventional multiplication.

4) Vedic mathematics will continue in spite of the availability of electronic calculators or other calculating gadgets.

\section{Acknowledgements}

The authors express their sincere gratitude to the editor and his team for valuable guidance. Further, the authors are indebted to Mr. Prakash Atul, Director High Radius Corporation, Houston, Texas (US), Mrs. Apoorva Mathur, Mrs Richa, Mr. Nitish and Mrs. Reeta Mathur for encouraging them to conduct research in this field and for providing assistance in verification as well as computerization of this paper.

\section{References}

[1] Tirtha, J.S.B.K. (2013) Vedic Mathematics or Sixteen Simple Mathematical Formulae from the Vedas, Delhi, 40-48. 
[2] Guthrie, G. (1997) Vedic Computation: Redefining Computer Science in the Light of Maharishi Vedic Science, Fiarfield, 195, 210.

[3] John M. (1998) Muehlman Maharishi's Vedic Mathematics in Elementary Education: Developing All Knowingness to Improve Affect, Achievement, and Mental Computation, Fiarfield, 58.

[4] Dhivyadeepa, E. (2014) International Multidisciplinary E-Journal. Vedic Activities in the Skills of Arithmetic, Coimbatore, 9214.

[5] Kavita and Goyal, U. (2013) Performance Analysis of Various Vedic Techniques for Multiplication. International Journal of Engineering Trends and Technology, 4, 232. http://www.internationaljournalssrg.org

[6] Benjamin, A. and Shermer, M. (2006) Secrets of Mental Math: The Mathemagician's Guide to Lightning Calculation and Amazing Math Tricks, Three Rivers Press, New York, 138-145.

[7] Jain, S. and Jagtap, V.S. (2014) Vedic Mathematics in Computer: A Survey. International Journal of Computer Science and Information Technologies, 5, 7458-7459.

[8] Nishant, G.D. and Mahajan, R. (2017) Ancient Indian Vedic Mathematics Based Multiplier Design for High Speed and Low Power Processor. International Journal of Advanced Research in Electrical, Electronics and Instrumentation Engineering, 95, 2320-3765.

[9] Saha, P., Banerjee, A., Dandapat, A. and Bhattacharyya, P. (2011) Vedic Mathematics Based 32-Bit Multiplier Design for High Speed Low Power Processors. International Journal on Smart Sensing and Intelligent Systems, 4, 272-274.

[10] Fernandes, C. and Borkar, S. (2013) Application of Vedic Mathematics in Computer Architecture. International Journal of Research in Engineering and Science, 1, 40-45.

[11] Jayakumar, S. and Sumathi, A. (2016) High-Performance FIR Filter Implementation Using Anurupye Vedic Multiplier. Scientific Research Publishing-Circuits and Systems, 7, 3723-3733. http://www.scirp.org/journal/cs

[12] Kamal, S. and Toor, C.K. (2015) Implementation of Vedic Multiplier in Image Compression Using Discrete Wavelet Transform (DWT) Algorithm. IJSRD-International Journal for Scientific Research \& Development, 3, 2259, 2261.

[13] Magar, V.B. (2013) Area and Speed Wise Superior Multiply and Accumulate Unit Based on Vedic Multiplier. Journal of Engineering Research and Applications, 3, 994-999.

[14] Vyas, D. and Jain, N. (2015) New Robust Reduced-Bit Multiplication Algorithm by using Vedic Mathematics. International Journal of Engineering Technology and Applied Science, 1, 2.

[15] Pokhriyal, N., et al. (2013) Compressor Based Area-Efficient Low-Power $8 \times 8$ Vedic Multiplier. Journal of Engineering Research and Applications, 3, 1469-1472.

[16] Kavita, H.D. and Mrs. Dharmambal (2015) The Application of Vedic Mathematics for High Speed Multiplier in FIR Filter Design. International Journal of Engineering Research and General Science, 3, 366-367. 
Submit or recommend next manuscript to SCIRP and we will provide best service for you:

Accepting pre-submission inquiries through Email, Facebook, LinkedIn, Twitter, etc. A wide selection of journals (inclusive of 9 subjects, more than 200 journals)

Providing 24-hour high-quality service

User-friendly online submission system

Fair and swift peer-review system

Efficient typesetting and proofreading procedure

Display of the result of downloads and visits, as well as the number of cited articles Maximum dissemination of your research work

Submit your manuscript at: http://papersubmission.scirp.org/

Or contact ajcm@scirp.org 